\title{
A message from C. R. Rao
}

Published online 20 July 2020

I am honored and touched that you are celebrating my centenary year. I appreciate your thoughtfulness and kindness.

I started my academic career with a master's degree in mathematics. In the early 1940s, the jobs in the field of mathematics were limited. I then stumbled into statistics by chance. Statistics was a relatively new subject in India then. I was one of the first five students to get a master's degree in statistics from Calcutta University. My career in statistics progressed as I got a Ph.D. in Statistics from Cambridge University and I continued to work at the Indian Statistical Institute in Calcutta. At the Institute, there was a rich, supportive environment to pursue research and to teach, in addition to my administrative responsibilities. After retirement from the Institute, I worked at several universities in the United States including the University of Pittsburgh and the Pennsylvania State University, which further enriched my experiences.

I was fortunate to have made some fundamental contributions to the field of statistics and to see the impact of my work in furthering research. In my lifetime, I have seen statistics grow into a strong independent field of study based on mathematical, and more recently computational, tools. Its importance has spread across numerous areas such as business, economics, health and medicine, banking, management, physical, natural, and social sciences.

Statistics is the science of learning from data. Today is the age of data revolution. There is therefore, a heightened need for statistics - both in terms of training in statistics to help analyze and interpret the data, and in terms of research to answer new questions arising from the data. The demand for statisticians is growing worldwide. For instance, the US Bureau of Labor lists statistics as one of the fastest growing career fields - and predicts it will grow by $33 \%$ between 2016 and 2026.

Therefore, we have our work cut out for us as researchers and as teachers. This is the challenge for all of you.

I have some intellectual satisfaction for the esteem I earned from my peers in my field who introduced technical terms in statistical inference, attaching my name to them.

My greatest contribution is the encouragement I provided to my Ph.D. students, 51 of them (as of 2019), some of who have made outstanding contributions to statistics. They have in turn produced $649 \mathrm{Ph}$.D. students. This is a matter of pride to me.

Thank you very much for arranging this event to celebrate my birthday. My best wishes and blessings to all of you-my friends and well-wishers. 